\title{
Cholestatic syndrome as initial manifestation of pancreatic metastasis of papillary thyroid carcinoma: case report and review
}

Mariana Yoshii Tramontin ${ }^{1,2}$

http://orcid.org/0000-0002-9168-414X

Paulo Antônio Silvestre de Faria ${ }^{3}$

http://orcid.org/0000-0003-1817-4888

Cristina Moreira do Nascimento ${ }^{3}$

https://orcid. org/0000-0002-6980-0490

Cibele de Aquino Barbosa ${ }^{4}$

http://orcid.org/0000-0003-2681-0928

Maria de Fátima Rei Pereira Barros ${ }^{5}$

http://orcid.org/0000-0001-8261-162X

Aniela Rodrigues Gomes de Barros ${ }^{5}$

http://orcid. org/0000-0002-1923-8196

Rafaela Cardoso de Carvalho 5

http:///orcid.org/0000-0001-6473-7480

Antônio Kneipp Pitta de Castro Neto 5

http://orcid.org/0000-0001-5199-6424

Fernanda Accioly de Andrade ${ }^{1}$

http://orcid.org/0000-0002-6687-0506

Rossana Corbo'

https://orcid. org/0000-0001-8725-7455

Fernanda Vaisman ${ }^{1,6}$

https://orcid.org/0000-0002-6835-7108

Daniel Bulzico ${ }^{1,2}$

http://orcid.org/0000-0003-1270-7241

\section{SUMMARY}

Most papillary thyroid carcinomas (PTC) harbor excellent prognosis. Although rare, distant metastases normally occur in lungs and/or bones. Here we describe a rare case of pancreatic metastasis presenting with rapid onset cholestatic syndrome. A literature review was also performed. A 73-yearold man with a high risk PTC was submitted to total thyroidectomy (TT) followed by radioiodine therapy. After initial therapy, he persisted with progressive rising serum thyroglobulin levels but with no evidence of structural disease. Recently, the patient presented with a rapid onset and progressive cholestatic syndrome. A $4 \mathrm{~cm}$ lesion in pancreas was identified, with echoendoscopy fine-needle aspiration biopsy (FNAB) confirming a pancreatic metastasis from PTC. The patient was submitted to a successful pancreaticoduodenectomy. Pancreatic metastases of PTC are rare and few long-term follow-up data are available to guide management. Fourteen cases were former reported, mean age was 65.7 years-old with mean time between PTC and pancreatic metastasis diagnosis of 7.9 years. Nine of them had another distant metastasis, nine were diagnosed by FNAB and just two received sorafenib. Arch Endocrinol Metab. 2020;64(2):179-84

\author{
1 Unidade de Endocrinologia \\ Oncológica, Instituto Nacional de \\ Câncer José Alencar Gomes da Silva \\ (INCA), Rio de Janeiro, RJ, Brasil \\ ${ }^{2}$ Serviço de Endocrinologia, \\ Hospital Federal da Lagoa, \\ Rio de Janeiro, RJ, Brasil \\ ${ }^{3}$ Divisão de Patologia, Instituto \\ Nacional de Câncer José \\ Alencar Gomes da Silva (INCA), \\ Rio de Janeiro, RJ, Brasil \\ ${ }^{4}$ Seção de Cirurgia \\ Abdominopélvica, Instituto \\ Nacional de Câncer José \\ Alencar Gomes da Silva (INCA), \\ Rio de Janeiro, RJ, Brasil \\ ${ }^{5}$ Serviço de Cirurgia Geral \\ e Oncológica, Hospital \\ Central da Polícia Militar, Rio \\ de Janeiro, RJ, Brasil \\ ${ }^{6}$ Pós-graduação em Endocrinologia \\ da Faculdade de Medicina \\ da Universidade Federal do \\ Rio de Janeiro (UFRJ), Rio \\ de Janeiro, RJ, Brasil
}

Correspondence to:

Mariana Yoshii Tramontin

Unidade de Endocrinologia Oncológica,

Instituto Nacional de Câncer, Rua do Resende, 128 20231-092 - Rio de Janeiro, RJ, Brasil mariyoshiitramontin@yahoo.com.br

Received on June/3//2019 Accepted on Sept/26/2019

DOI: 10.20945/2359-3997000000215

\section{INTRODUCTION}

$\mathrm{T}$ hyroid cancer is the most common endocrine malignancy. Incidence has almost tripled since 1970, representing $3.1 \%$ of all new cancer cases but being responsible for just $0.3 \%$ of all cancer deaths in the United States according to SEER (Surveillance,
Epidemiology, and End Results Program) database. Around $90 \%$ is derived from follicular cells and PTC is the most prevalent histological type (1). PTC generally has good prognosis expressed by $98 \%$ of overall survival rate. However up to $2.3-4.3 \%$ presents with distant metastasis at diagnosis $(2,3)$. 
Distant metastasis is the most important death-risk prognostic factor, with stage IV patients presenting with disease-specific survival at 5 and 10 years of $65 \%$ and $45 \%$ respectively (3). Lungs, bones, thoracic lymph nodes and nervous system are the most common organs involved (4). Unusual metastatic sites have been described in skin (5), pancreas (6), eye (7), kidney (8), adrenal (9), breast (10) and liver (11), but they do not always represent an additional negative prognostic factor for disease outcome (12).

Metastatic pancreatic tumors are rare and account for less than $4 \%$ of all pancreatic malignancies (13). The most common primary neoplasm is the kidney, with PTC metastases being extremely rare. Fourteen cases have been described so far, occurring up to 15 years after initial therapy. The treatments modalities described varied from surgery, chemotherapy, tyrosine kinase inhibitors (TKI), and active surveillance $(6,10,14-24)$. Regarding survival, the benefit of metastasectomy has been observed for renal cell carcinoma metastases (25). About PTC, of the 7 cases submitted to metastasectomy and who had follow-up information, 4 died of the disease, 1 died of acute myocardial infarction, 1 had disease progression and $\mathrm{l}$ was alive at 36 months. Here we report one case of pancreatic metastasis from PTC initially presented as cholestatic syndrome with successful duodenopancreatectomy.

\section{CASE DESCRIPTION}

A 73-year-old man, presented in 2012 with a large goiter, and suspicious lymph-nodes palpable in lateral neck. He was submitted to total thyroidectomy (TT) with central and right lateral lymphadenectomy (levels $\mathrm{I}-\mathrm{V}$ ) in 2012. Pathology study revealed a $5.5 \mathrm{~cm}$ classical papillary carcinoma with extra-thyroidal extension to cervical muscles, neoplastic emboli to lymphatics vessels, and gross invasion of the internal jugular vein. Metastases to 24 of 25 right cervical lymph nodes were observed - pT4aNlbMx (AJCC/TNM $8^{\text {th }}$ edition). Initial non-stimulated thyroglobulin $(\mathrm{Tg})$ was of $5.81 \mathrm{ng} / \mathrm{mL}$, with undetectable anti-Tg. The initial postoperative images (cervical ultrasound and chest computed tomography) showed no suspicious findings. After surgery the patient received radioiodine therapy (RAI) with $200 \mathrm{mCi}$ of ${ }^{131} \mathrm{I}$. Post-therapy wholebody scan (WBS) was positive in right hemithorax although no structural disease was evident in thorax computed tomography (CT). During the first five years of follow-up he persisted with rising serum Tg levels but with no correspondent structural image in neck ultrasound, chest CT, or radioiodine WBS. Finally, in $2016{ }^{18} \mathrm{~F}-\mathrm{FDG}$ PET revealed suspicious right posterior neck (SUV 7.7) and right supraclavicular lymph-nodes (SUV 15.9). An additional surgical neck dissection removed metastatic lymph nodes in August 2016.

Despite the additional surgical treatment, during the past year he evolved again with rapid rising of $\mathrm{Tg}$ levels (Tg: $32.8 \mathrm{ng} / \mathrm{mL}$, TSH: $0.1 \mathrm{mU} / \mathrm{L}$ ) and again with unidentified structural loco-regional disease and ${ }^{18} \mathrm{~F}-\mathrm{FDG}$ PET was requested.

In January 2018, while waiting for ${ }^{18} \mathrm{~F}-\mathrm{FDG}$ PET, the patient actively sought out the outpatient clinic because of altered liver biochemistry: aspartate aminotransferase: $210 \mathrm{UI} / \mathrm{L}$ (normal range: < 40 $\mathrm{UI} / \mathrm{L}$ ), alanine aminotransferase: $858 \mathrm{UI} / \mathrm{L}$ (reference range < 41UI/L), alkaline phosphatase: $173 \mathrm{UI} / \mathrm{L}$ (reference range: 40-129 UI/L), gamma glutamyl transferase: $739 \mathrm{UI} / \mathrm{L}$ (reference range $<60 \mathrm{UI} / \mathrm{L}$ ). Bilirubin was normal (total bilirubin: $0.9 \mathrm{mg} / \mathrm{dL}$, direct bilirubin: $0.5 \mathrm{mg} / \mathrm{dL}$ ) and the patient was asymptomatic. Drug-induced hepatoxicity and viral hepatitis were excluded. One week later, hepatogram was repeated (AST: 240, ALT: 713, GGT: 1298, total bilirubin: 1.5, direct bilirubin: 0.9 ), and the patient began to present jaundice, nausea, anorexia, and fatigue. Weight loss started to become evident, jaundice worsened and next week laboratory showed AST: 261, ALT: 687, GGT: 1150, total bilirubin: 10.2 , direct bilirubin: 8.2 , albumin and prothrombin time were normal.

The ${ }^{18} \mathrm{~F}-\mathrm{FDG}$ PET revealed a $2.8 \mathrm{~cm}$ expansive lesion in the head of the pancreas (SUV 10.6) in contact with duodenum, presenting partially defined limits with marked dilatation of biliary tract. At that occasion, $\mathrm{Tg}$ was of $281.3 \mathrm{ng} / \mathrm{mL}$. He was referred to a CT-guided external percutaneous biliary drainage and fine-needle endoscopic ultrasound biopsy. Cytology study was consistent with metastatic PTC. Cell-block immunohistochemistry was positive to TTF-1.

After multidisciplinary discussion, in April 2018 the patient underwent a pancreaticoduodenectomy performed by an extended subcostal incision at Hospital Central da Polícia Militar. The pancreatogastrostomy was the technique of choice for pancreatic reconstruction after finding a soft pancreatic stump and non-dilated main duct. Double omental flap around the anastomosis was performed. The hepaticojejunostomy 
and gastroentero anastomosis was made in single loop and a cavity drain was setted up in the right flank. The transparietal drain was removed in the $10^{\text {th }}$ day after surgery. Patient had a favorable evolution getting hospital discharge in the $13^{\text {th }}$ day post operative without any complications. The pathology study described an infiltrative papillary architectural pattern carcinoma of $3.5 \times 3.0 \mathrm{~cm}$, compromising pancreatic tissue, presenting morphological characteristics compatible with metastatic PTC. Immunohistochemistry study was positive for $\mathrm{Tg}$. After surgery, suppressed thyroglobulin was $241.3 \mathrm{ng} / \mathrm{mL}$. Sorafenib was initiated in October, 2018 at full dosage $(800 \mathrm{mg} \mathrm{q}$.d.) and after one month the dose was reduced to $600 \mathrm{mg}$ q.d. due to palmar-plantar erythrodysesthesia syndrome. Imaging studies show stable disease during sorafenb treatment. The patient is currently asymptomatic and attending outpatient clinics under surveillance at Instituto Nacional de Câncer José Alencar Gomes da Silva e Hospital Federal da Lagoa.

\section{DISCUSSION}

Here we describe a case of pancreatic metastasis from PTC. Occurrence is rare, moreover is the first time that altered liver biochemistry and typical symptoms of cholestatic syndrome are the initial presentation. Of the reported cases, 35\% describe isolated abdominal pain as initial symptom and $28 \%$ asymptomatic elevated $\mathrm{Tg}$ $(6,14)$. Even thought the clinicopathologic features of unusual metastasis in PTC are not well established (12), previous known characteristics of poor prognosis and high risk of general distant metastasis in our case included older age and male gender additionally to high risk of recurrence, TNM classification (7th TNM: IVc, 8th TNM: IVb) and the development of radioactive iodine refractoriness.

Many of PTC metastasizes to regional lymph nodes but when the metastases are distant, lung and bone are the compromised sites. First described by Sugimura and cols. (15), metastases of PTC to pancreas are extremely rare, as evidenced by just 14 previously published cases (6,10,14-23). We performed a PubMed based research for previous reported cases using the following terms: "pancreatic metastasis AND thyroid cancer" during 1991 and July 2019. Only articles originally published in English language were included. Fourteen cases were found and are summarized in Table 1. Incidence of pancreatic metastasis was 1.8 times higher in male gender and from the 12 cases that reported histology,
7 were PTC, 3 tall cell variant and 2 follicular cell variant. Mean diagnosis age was 65.7 (39-84), 7.9 years after TT. About mortality risk, 5 were T4, 10 had lymph node involvement, 6 had other distant metastasis at the time of pancreatic metastasis but another 3 cases discovered it after. They comprised lung ( 8 cases), bone (4), liver (2), brain (1), adrenal (1) and omentum (1).

Metastasis represent $1,8 \%$ to $4 \%$ of pancreatic masses and are generally related to kidney, skin, lung and breast malignancies $(26,27)$. Differently from the usual pattern, $98 \%$ of pancreatic metastasis manifest as single lesions (27), being a potential diagnostic pitfall. Although not determinative, metastatic lesions are less likely with increasing age, presence of symptoms (abdominal pain, diarrhea, or weight loss), elevated bilirubin and arterial invasion on imaging when compared with pancreatic adenocarcinoma (28). Even though, our patient was an aged man with expressive weight loss and conjugated hyperbilirubinemia.

Since non-invasive methods are not accurate enough, endoscopic ultrasound-guided fine-needle biopsy has become the preferred method for diagnosis of pancreatic masses. Reported sensitivity and specificity for metastatic lesions are $84.9 \%$ and $100 \%$ respectively (28). Cytology generally displays cytomorphologic features similar to those of the primary neoplasm (27).

Most previously reported patients have known advanced cancer with other organs metastases at the time pancreatic lesion is discovered $(10,14,16-19,21,22)$. Even though time for diagnosis was variable from one month to fifteen years after TT, and as an exception, in one case PTC diagnosis was done after pancreatectomy (10). The majority of patients with PTC and pancreatic metastases could be defined as iodine refractory, since biological and clinical features such as the progressive disease pattern despite previous high dose ${ }^{131}$ I therapy, and high ${ }^{18} \mathrm{~F}$-FDG uptake were commonly found. Our case demonstrated positivity of the pancreatic lesion at ${ }^{18} \mathrm{~F}-\mathrm{FDG}$, as the same way as $100 \%$ of reported cases that performed it. Despite this, no anaplastic features were found in our pathology report.

For most metastatic well differentiated thyroid cancers, TT and radioiodine followed by TSH suppression are the gold standard therapy. However, in up to $30 \%$ of these cases iodine refractoriness will occur during follow-up $(29,30)$. In this setting, 10-year survival reduces to $10 \%(30)$, and therapy approaches must be individualized according to factors such as disease volume, burden of disease, and symptomatic progression (31). 


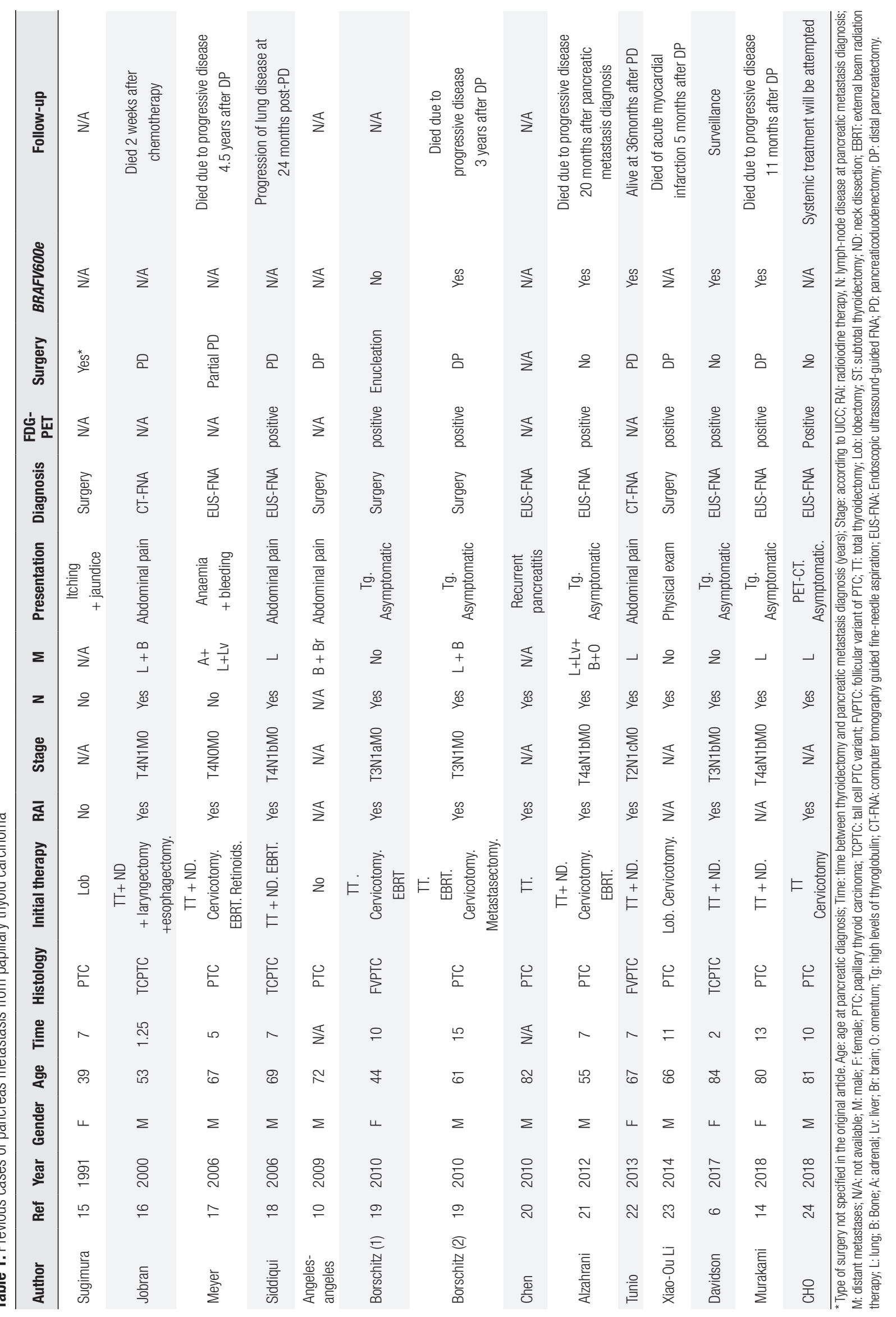


Localized therapy directed to single metastasis patients must be the first line approach whenever possible in these patients. In a retrospective study, HO PAK and cols. (32) analyzed 47 metastasectomies (none in the pancreas) and found cumulative survival of $50.2 \pm 12.5 \%$ at 10 years after the first metastasectomy. Experienced surgeons in specialized centers are able to perform pancreaticoduodenectomy with mortality rates as low as $2 \%$ in a population composed of more than $70 \%$ of aged over 75-years-old (33). Although surgical resections of pancreatic metastasis are not well established, consideration has to be done in cases of isolated metastasis or very symptomatic patients, once metastasectomy could reduce tumor burden and improve both survival and quality of life. Ten of the fourteen cases reported managed the pancreatic metastasis with surgery (Table 1). For patients with multiple metastases, especially those with symptomatic progression, TKI are the current treatment of choice with well described improvement in diseaseprogression free interval $(34,35)$. To date, sorafenib and lenvatinib are the only two FDA approved molecules for this purpose. In the pancreatic metastasis, 2 cases reported the use of sorafenib, one evolved with disease progression (21) and the other had good response (22).

In conclusion, this is the first time a pancreatic metastasis of PTC presents as cholestatic syndrome. Despite rare, secondary malignancies in the pancreas have to be considered and endoscopic ultrasound is an important diagnostic tool that can lead to correct diagnosis and proper management. More experience is needed in the treatment of these metastases, meanwhile, TKI and duodenopancreatectomy should be considered.

Funding: this research did not receive any specific grant from any funding agency in the public, commercial or not-for-profit sector.

Ethical approval: informed consent was obtained from all individual participants included in the study.

Disclosure: no potential conflict of interest relevant to this article was reported.

\section{REFERENCES}

1. Sherman SI. Thyroid carcinoma. Lancet. Lancet. 2003;361(9356):501-11.

2. Shaha AR, Shah JP, Loree TR. Differentiated thyroid cancer presenting initially with distant metastasis. Am J Surg. 1997; 174(5):474-6.

3. Sugitani I, Fujimoto Y, Yamamoto N. Papillary thyroid carcinoma with distant metastases: Survival predictors and the importance of local control. Surgery. 2008;143(1):35-42.
4. Wang LY, Palmer FL, Nixon IJ, Thomas D, Patel SG, Shaha AR, et al. Multi-organ distant metastases confer worse disease-specific survival in differentiated thyroid cancer. Thyroid. 2014;24(11):1594-9.

5. Cohen PR. Metastatic papillary thyroid carcinoma to the nose: report and review of cutaneous metastases of papillary thyroid cancer. Dermatol Pract Concept. 2015;5(4):7-11.

6. Davidson M, Olsen RJ, Ewton AA, Robbins RJ. Pancreas metastases from papillary thyroid carcinoma: A review of the literature. Endocr Pract. 2017 Dec;23(12):1425-9.

7. OzpacaciT MM, Tamam MO, Leblebici C, Yildiz K, Uyanik E, Eltutar $\mathrm{K}$. Intraocular and orbital metastasis as a rare form of clinical presentation of insular thyroid cancer. Ann Endocrinol (Paris). 2012;73(3):222-4.

8. Gamboa-Dominguez A, Tenorio-Villalvazo A. Metastatic follicular variant of papillary thyroid carcinoma manifested as a primary renal neoplasm. Endocr Pathol. 1999 Autumn;10(3):256-8.

9. Batawil N. Papillary thyroid cancer with bilateral adrenal metastases. Thyroid. 2013;23(12):1651-4.

10. Angeles-Angeles A, Chable-Montero F, Martinez-Benitez B, Albores-Saavedra J. Unusual metastases of papillary thyroid carcinoma: Report of 2 cases. Ann Diagn Pathol. 2009;13(3):189-96.

11. VandenBussche CJ, Gocke CD, Li QK. Fine-needle aspiration of metastatic papillary thyroid carcinoma found in the liver. Diagn Cytopathol. 2013;41(5):418-24.

12. Farina E, Monari F, Tallini G, Repaci A, Mazzarotto R, Giunchi F, et al. Unusual thyroid carcinoma metastases: A case series and literature review. Endocr Pathol. 2016;27(1):55-64.

13. Adsay NV, Andea A, Basturk O, Kilinc N, Nassar H, Cheng JD. Secondary tumors of the pancreas: An analysis of a surgical and autopsy database and review of the literature. Virchows Arch. 2004;444(6):527-35.

14. Murakami Y, ShimuraT, Okada R, Kofunato Y, Ishigame T, Yashima $\mathrm{R}$, et al. Pancreatic metastasis of papillary thyroid carcinoma preoperatively diagnosed by endoscopic ultrasound-guided fineneedle aspiration biopsy: A case report with review of literatures. Clin J Gastroenterol. 2018 Dec;11(6):521-9.

15. Sugimura H, Tamura S, Kodama T, Kakitsubata Y, Asada K, Watanabe K. Metastatic pancreas cancer from the thyroid; clinical imaging mimicking non functioning islet cell tumor. Radiat Med. 1991;9(5):167-9.

16. Jobran R, Baloch ZW, Aviles V, Rosato EF, Schwartz S, LiVolsi VA. Tall cell papillary carcinoma of the thyroid: Metastatic to the pancreas. Thyroid. 2000;10(2):185-7.

17. Meyer A, Behrend $M$. Is pancreatic resection justified for metastasis of papillary thyroid cancer? Anticancer Res. 2006;26(3B):2269-73.

18. Siddiqui AA, Olansky L, Sawh RN, Tierney WM. Pancreatic metastasis of tall cell variant of papillary thyroid carcinoma: Diagnosis by endoscopic ultrasound-guided fine needle aspiration. JOP. 2006;7(4):417-22.

19. BorschitzT, Eichhorn W, Fottner C, HansenT, Schad A, SchadmandFischer $\mathrm{S}$, et al. Diagnosis and treatment of pancreatic metastases of a papillary thyroid carcinoma. Thyroid. 2010;20(1):93-8.

20. Chen L, Brainard JA. Pancreatic metastasis from papillary thyroid carcinoma diagnosed by endoscopic ultrasound-guided fine needle aspiration: A case report. Acta Cytol. 2010;54(4):640-4.

21. Alzahrani AS, AIQaraawi $A$, Al Sohaibani F, Almanea $H$, Abalkhail H. Pancreatic metastasis arising from a braf(v600e)-positive papillary thyroid cancer: The role of endoscopic ultrasoundguided biopsy and response to sorafenib therapy. Thyroid. 2012;22(5):536-41.

22. Tunio MA, Alasiri M, Riaz K, Alshakweer W. Pancreas as delayed site of metastasis from papillary thyroid carcinoma. Case Rep Gastrointest Med. 2013;2013;386263. 
23. Xiao-Ou Li, Zheng-Peng Li, Ping Wang, Cheng-Lin Li, Ji-Hua Wu, Jian-Zhong Zhang, et al. Pancreatic metastasis of papillary thyroid carcinoma: A case report with review of the literature. Int J Clin Exp Pathol. 2014;7(2):819-22.

24. Cho M, Acosta-Gonzalez G, Brandler TC, Basu A, Wei XJ, Simms A. Papillary thyroid carcinoma metastatic to the pancreas: Case report. Diagn Cytopathol. 2019;47(3):214-7.

25. Sperti C, Moletta L, Patane G. Metastatic tumors to the pancreas: The role of surgery. World J Gastrointest Oncol. 2014;6(10):381-92.

26. Olson MT, Wakely PE Jr, Ali SZ. Metastases to the pancreas diagnosed by fine-needle aspiration. Acta Cytol. 2013;57(5): 473-80.

27. Waters L, Si Q, Caraway N, Mody D, Staerkel G, Sneige N. Secondary tumors of the pancreas diagnosed by endoscopic ultrasound-guided fine-needle aspiration: A 10-year experience. Diagn Cytopathol. 2014;42(9):738-43.

28. Krishna SG, Bhattacharya A, Ross WA, Ladha H, Porter K, Bhutani MS, et al. Pretest prediction and diagnosis of metastatic lesions to the pancreas by endoscopic ultrasound-guided fine needle aspiration. J Gastroenterol Hepatol. 2015;30(10):1552-60.

29. Schlumberger M,Tubiana M, DeVathaire F, Hill C, Gardet P,Travagli $\mathrm{JP}$, et al. Long-term results of treatment of 283 patients with lung and bone metastases from differentiated thyroid carcinoma. J Clin Endocrinol Metab. 1986;63(4):960-7.
30. Durante C, Haddy N, Baudin E, Leboulleux S, Hartl D, Travagli JP, et al. Long-term outcome of 444 patients with distant metastases from papillary and follicular thyroid carcinoma: Benefits and limits of radioiodine therapy. J Clin Endocrinol Metab. 2006;91(8):2892-9.

31. Haugen BR, Alexander EK, Bible KC, Doherty GM, Mandel SJ, Nikiforov YE, et al. 2015 american thyroid association management guidelines for adult patients with thyroid nodules and differentiated thyroid cancer: The american thyroid association guidelines task force on thyroid nodules and differentiated thyroid cancer. Thyroid. 2016;26(1):1-133.

32. Pak H, Gourgiotis L, Chang WI, Guthrie LC, Skarulis MC, Reynolds $\mathrm{JC}$, et al. Role of metastasectomy in the management of thyroid carcinoma:The nih experience. J Surg Oncol. 2003;82(1):10-8.

33. Schmidt CM, Turrini O, Parikh P, House MG, Zyromski NJ, Nakeeb A, et al. Effect of hospital volume, surgeon experience, and surgeon volume on patient outcomes after pancreaticoduodenectomy: A single-institution experience. Arch Surg. 2010 Jul;145(7):634-40.

34. Brose MS, Nutting CM, Jarzab B, Elisei R, Siena S, Bastholt $L$, et al. Sorafenib in radioactive iodine-refractory, locally advanced or metastatic differentiated thyroid cancer: A randomised, doubleblind, phase 3 trial. Lancet. 2014;384(9940):319-28.

35. Schlumberger M, Tahara M, Wirth LJ, Robinson B, Brose MS, Elisei $R$, et al. Lenvatinib versus placebo in radioiodine-refractory thyroid cancer. N Engl J Med. 2015;372;621-30. 